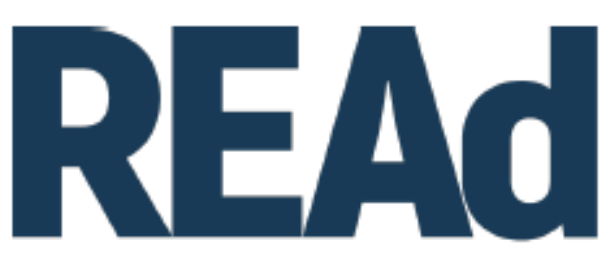

Revista Eletrônica de Administração

\title{
A FORMAÇÃO DO MERCADO DE ALIMENTOS ORGÂNICOS NO BRASIL: UMA ANÁLISE HISTÓRICA A PARTIR DO AGENCIAMENTO DAS PRÁTICAS REPRESENTACIONAIS DA REVISTA A LAVOURA ${ }^{1}$
}

\author{
Daniel de Oliveira Barata Merabet ${ }^{2}$ \\ Denise Franca Barros ${ }^{3}$
}

http://dx.doi.org/10.1590/1413-2311.313.102382

\begin{abstract}
RESUMO
$\mathrm{O}$ artigo tem por objetivo explorar como o agenciamento das práticas representacionais presentes nas reportagens da revista A Lavoura produziu versões do mercado de produtos orgânicos no período 1990-2007. A publicação é editada pela Sociedade Nacional de Agricultura desde 1897 e que, em virtude de uma ampla distribuição, alcança sindicatos, universidades, centros de pesquisa, bibliotecas, empresas do agronegócio entre outros. Em termos teóricos, a pesquisa foi informada por conceitos vinculados aos Estudos Construtivistas de Mercado, desenvolvidos em marketing, e pela perspectiva histórica reorientacionista, desenvolvida no âmbito dos estudos organizacionais, para acessar versões do mercado localizadas no passado. O percurso metodológico foi constituído por um estudo de caso histórico de orientação indutiva e de corte longitudinal. Em decorrência do processo de análise, três versões hegemônicas para o mercado de produtos orgânicos foram produzidas ao longo do período considerado. Os resultados apontam para a existência de dinâmicas de inclusão e de marginalização de atores humanos e não-humanos presentes no processo de agenciamento das práticas representacionais e, por conseguinte, nas versões de mercado. Recomenda-se que essas dinâmicas sejam reconhecidas por pesquisas futuras interessadas em investigar questões ideológicas, sociais e de políticas públicas que cercam os processos de formação de mercado.
\end{abstract}

Palavras-chave: Mercado de Produtos Orgânicos. Estudos Construtivistas de Mercado. Agenciamento Sociotécnico. Práticas Representacionais. Perspectiva Histórica.

\footnotetext{
${ }^{1}$ Recebido em 27/4/2020, aprovado em 24/2/2021.

2 Pesquisador independente; Doutor em Administração pela Universidade do Grande Rio (Unigranrio); Rio de Janeiro - RJ (Brasil); https://orcid.org/0000-0003-4582-3898; danielmerabet@hotmail.com.

${ }^{3}$ Universidade do Grande Rio (Unigranrio) - Programas de Pós-Graduação em Administração e de Humanidades, Cultura e Artes; Rio de Janeiro - RJ (Brasil); https://orcid.org/0000-0003-1640-6171; denise.fb@globo.com.
} 


\section{THE FORMATION OF THE ORGANIC FOOD MARKET IN BRAZIL: A HISTORICAL ANALYSIS BASED ON THE AGENCEMENT OF REPRESENTATIONAL PRACTICES INSIDE THE MAGAZINE A LAVOURA}

The purpose of this article is to explore how the agency of representational practices present in the magazine A Lavoura produced different organic market versions in the 1990-2007 period. Published by the Brazilian National Agriculture Society since 1897 and which, due to its wide distribution, reaches unions, universities, research centers, libraries, agribusiness companies, among others. In theoretical terms, a research was informed by the Constructivist Market Studies developed in marketing and by the historical re-orientationist perspective developed within the scope of organizational studies to access market versions located in the past. The methodological path consisted of a longitudinal historical case study with an inductive orientation. As a result of the analysis process, three hegemonic versions for the organic products market were produced over the period considered. The results point to the existence of dynamics of inclusion and marginalization of human and non-human actors present in the process of the agencement of representational practices and, therefore, in the market versions. It is recommended that these dynamics should be recognized by future research interested in investigating ideological, social and public policy issues that surround the processes of market formation.

Keywords: Organic Food Market. Constructivist Market Studies. Socio-technical Agencement. Representational Practices. Historical Perspective.

\section{LA FORMACIÓN DEL MERCADO DE ALIMENTOS ORGÁNICOS EN BRASIL: UN ANÁLISIS HISTÓRICO BASADO EN LA ORGANIZACIÓN DE PRÁCTICAS REPRESENTACIONALES DENTRO DE LA REVISTA A LAVOURA}

El propósito de este artículo es explorar cómo la agencia de prácticas representativas presente en la revista A Lavoura há producido diferentes versiones del mercado orgánico en el período 1990-2007. Publicado por la Sociedad Nacional de Agricultura de Brasil desde 1897 y que, por su amplia difusión, llega a sindicatos, universidades, centros de investigación, bibliotecas, empresas agroindustriales, entre otros. En términos teóricos, la presente investigación fue informada por los Estudios Constructivistas de Mercado desarrollados en marketing y por la perspectiva histórica reorientacionista desarrollada en el ámbito de los estudios organizacionales para acceder a versiones de mercado ubicadas en el pasado. El recorrido metodológico consistió en un estudio de caso histórico longitudinal con orientación inductiva. Como resultado del proceso de análisis, durante el período considerado se produjeron tres versiones hegemónicas para el mercado de productos orgánicos. Los resultados apuntan a la existencia de dinámicas de inclusión y marginación de actores humanos y no humanos presentes en el proceso de agenciamiento de prácticas representacionales y, por tanto, en las versiones de mercado. Se recomienda que estas dinámicas sean reconocidas por futuras investigaciones interesadas en investigar los temas ideológicos, sociales y de políticas públicas que rodean los procesos de formación de mercados. 
Palabras clave: Mercado de Productos Orgánicos. Estudios Constructivistas del Mercado. Agenciamiento Socio-técnico. Prácticas Representacionales. Perspectiva Histórica.

\section{INTRODUÇÃO}

O movimento dos Estudos Construtivistas de Mercado estabelecido em marketing (HARRISON; KJELLBERG, 2016; STIGZELIUS, 2018) ajudou a revigorar o interesse de pesquisas sobre como são formados os mercados. Influenciado em grande parte pelas propostas teóricas de Michel Callon (ARAUJO et al., 2010), tal movimento contraria a concepção hegemônica de que o mercado é um fenômeno eminentemente econômico, concreto e objetivo. Ao aplicar os pressupostos onto-epistemológicos da teoria ator-rede em suas investigações Callon (1998) argumenta que o mercado é um fenômeno em permanente construção que resulta de um processo de associação entre atores humanos e não humanos constituídos em uma trama, uma rede, que assegura por um período, a produção de uma determinada realidade de mercado. Para o autor portanto, mercado é um fenômeno sociomaterial.

A concepção de rede foi posteriormente substituída pelo conceito de agenciamento sociotécnico (ÇALISKAN; CALLON, 2010) que destaca a capacidade que um agregado de elementos heterogêneos possui para agir. Como recai sobre as práticas a função de qualificar a natureza de um agenciamento, entende-se que as práticas de mercado constituem agenciamentos sociotécnicos de mercado (CALLON, 2013). Portanto, o agenciamento das práticas de mercado, ao assegurar momentaneamente as associações entre atores humanos e não-humanos, age, produz versões de mercado (ARAUJO; KJELLBERG, 2016; HAGBERG, 2016).

As práticas representacionais figuram dentre as práticas de mercado (KJELLBERG; HELGESSON, 2006, 2007a) e a sua relevância está associada ao fato de descrições e representações abstratas sobre o fenômeno, como por exemplo, relatórios ou revistas setoriais, contribuírem para sua constituição. De forma mais específica, essas práticas revelam dinâmicas de negociação entre diversos atores implicando em quem integra, quem foi deslocado ou até mesmo quem foi excluído de uma dada representação de mercado.

O que ainda as pesquisas vinculadas aos Estudos Construtivistas de Mercado não deixaram claro é como foram produzidas versões de mercado no passado. Embora existam pesquisas que adotem uma perspectiva histórica (GEIGER; FINCH, 2016; HAGBERG, 2016; COCHOY et al., 2018) elas não se debruçam sobre como a realidade histórica pode ser reconstituída. Ressalta-se inclusive, que esse tipo de preocupação não integrava nem mesmo as 
pesquisas de Michel Callon (DUREPOS; MILLS, 2011). Desta forma, a aproximação com o movimento intitulado de "virada histórica", desenvolvido no âmbito dos estudos organizacionais, aponta para possibilidades promissoras para superar esta lacuna.

Dentre as diversas abordagens que o movimento de "virada histórica" abriga, argumenta-se, em sua vertente reorientacionista (USDIKEN; KIESER, 2004), que o passado resulta de um processo contínuo constituído por dimensões de poder e de legitimidade e que suscita nas pesquisas, reflexões críticas e de natureza ética. A esse entendimento do passado, portanto, não lhe é atribuído status ontológico realista. Especificamente, a proposta de Durepos e Mills (2011), por estar baseada nos mesmos pressupostos dos Estudos Construtivistas de Mercado, ganha proeminência por informar sobre como acessar versões da realidade localizadas no passado em tempo presente, ou seja, como acessar versões de mercado no passado.

Em função do exposto, a presente pesquisa tem por objetivo explorar como o agenciamento das práticas representacionais presentes nas reportagens da revista A Lavoura produziu versões do mercado de produtos orgânicos no período 1990-2007. A publicação é editada pela Sociedade Nacional de Agricultura desde 1897 e que, em virtude de uma ampla distribuição, alcança sindicatos, universidades, centros de pesquisa, bibliotecas, empresas do agronegócio entre outros. Neste sentido, argumenta-se que ao disseminar representações de mercado influencia a constituição do mesmo. Já a delimitação baseada nos produtos orgânicos é justificada pela pluralidade de atores envolvidos na formação deste mercado e coexistência de agenda de interesses econômicos, sociais e de políticas públicas (FONSECA, 2009; MOURA, 2017).

Embora a Sociedade Nacional de Agricultura adote uma perspectiva associada ao agronegócio (SNA, s/d), existe a expectativa de explorar como atores do governo, da sociedade civil e do terceiro setor, historicamente ligados à formação do mercado de produtos orgânicos, foram representados: Quem eram esses atores? Quais foram incluídos/excluídos ao longo do tempo? Como que uma nova configuração de atores, estabelecida a partir de práticas representacionais, altera agenciamentos implicando no enfraquecimento ou na promoção de novas versões do mercado de produtos orgânicos? Essas questões orientaram os movimentos iniciais da pesquisa.

Este artigo está dividido em 6 seções após a introdução. A primeira seção apresenta a relação entre dois conceitos vinculados ao Estudos Construtivistas de Mercado: o de agenciamento sociotécnico e o de práticas representacionais. Em seguida, discorre-se sobre a opção pela perspectiva reorientacionista para acessar versões do mercado localizadas no 
passado. Na terceira seção, o percurso metodológico desenvolvido para a operacionalização do quadro teórico é apresentado. Na quarta seção, são descritas três versões para o mercado de produtos orgânicos. Segue-se a seção de análise das versões com atenção para a forma com que as diferentes configurações do agenciamento das práticas representacionais implicam em dinâmicas de inclusão e marginalização de atores, humanos e não-humanos, ligados ao mercado de produtos orgânicos. As considerações finais bem como as sugestões para pesquisas futuras encerram este artigo.

\section{O MERCADO COMO CONSTRUÇÃO SOCIOMATERIAL: NOÇÕES DE AGENCIAMENTO E DE PRÁTICAS REPRESENTACIONAIS}

Em decorrência das discussões estabelecidas no campo conhecido como a nova sociologia econômica (SWEDBERG, 2003; SMELSER; SWEDBERG, 2005), os esforços em resgatar e problematizar a natureza do mercado, como fenômeno a ser pesquisado, têm recebido reconhecimento tanto em marketing (KJELLBERG et al., 2012; MASON et al., 2015) quanto estudos organizacionais (GEIGER; GROSS, 2017; COCHOY et al., 2018). Ao contrário do entendimento hegemônico do mercado como um fenômeno estritamente econômico, objetivo, neutro e concreto, a nova sociologia econômica o enraíza no tecido social (SWEDBERG, 2003; SMELSER; SWEDBERG, 2005). Decorrem deste movimento diversas possibilidades teóricas dentre as quais podem ser mencionadas: as redes de Granovetter (RAUD-MATTEDI, 2005), a perspectiva institucional de Fligstein (1996), a natureza performativa do conhecimento econômico de Callon (1998) e os regimes de justificação de Boltanski e Thevenot (2006).

A proposta de Callon (1998) lançou os fundamentos onto-epistemológicos do que se convencionou chamar em tempos mais atuais de Estudos Construtivistas de Mercado no âmbito da disciplina de marketing (HARRISON; KJELLBERG, 2016; STIGZELIUS, 2018). Para o autor, mercados são fenômenos em construção dadas as contínuas operações de enquadramento e de transbordamento realizadas por diversos atores humanos e não-humanos. Como resultado, implicam respectivamente na definição daqueles que constituem e daqueles que, por ser afetados positivamente ou negativamente, buscam reconhecimento ou até mesmo alterar a configuração do enquadramento vigente.

Callon (1998) aplica aos estudos de mercado os pressupostos da teoria ator-rede em que se destacam o princípio da simetria entre atores humanos e não-humanos na produção do que é "real" e o princípio da translação, que ajuda a compreender como ideias e conhecimento se 
movem em uma rede formada por entidades heterogêneas. Mercado, portanto, decorre de um processo de construção sociomaterial (KJELLBERG; HELGESSON, 2006).

Em desenvolvimento posterior, a concepção de arranjo sociotécnico (ou de rede) cedeu espaço ao conceito de agenciamento sociotécnico, sobretudo para destacar a capacidade de agir deste agregado de atores humanos e não-humanos (ÇALISKAN; CALLON, 2010). Como práticas específicas qualificam a natureza dos agenciamentos (CALLON, 2013), depreende-se que as práticas de mercado produzem agenciamentos sociotécnicos de mercado por meio de processos de translação que envolvem discursos, textos, narrativas, conhecimento científico, dispositivos materiais e agenda de interesse de indivíduos e organizações (ÇALISKAN; CALLON, 2010; COCHOY et al., 2016).

Dentre as diversas possibilidades para o estudo das práticas (HAGBERG, 2016; GHERARDI, 2016), a proposta de Kjellberg e Helgesson (2006; 2007a) merece destaque à medida em que oferece um importante recurso epistemológico para investigações que tenham mercado como fenômeno a ser explorado. Para os autores, as práticas de mercado podem ser classificadas em: a) práticas de troca, atividades que abrangem troca de bens e serviços entre produtores e consumidores; b) práticas normativas, atividades que contribuem para o funcionamento de um mercado a partir de um enquadramento estabelecido, por exemplo, por lei ou pela atuação de um determinado grupo de atores e; c) práticas representacionais, atividades que contribuem para descrição e produção de imagens, abstrações sobre mercado, como, por exemplo, relatórios setoriais. Tendo em vista os objetivos da presente pesquisa, a atenção será voltada para as práticas representacionais.

Como as práticas de mercado tangenciam questões controversas (BLANCHET; DEPEYRE, 2015) e com ampla repercussão social (GEIGER et al., 2014), as práticas representacionais, especificamente, permitem capturar as dinâmicas de negociação capazes de informar tanto quem e o que faz parte quanto quem e o que está excluído de um dado mercado. Neste sentido, as práticas representacionais participam das dinâmicas de formação de mercados implicando nas operações de enquadramento e de transbordamento e influenciando a configuração de agenciamentos que encerram posições tanto de hegemonia quanto de resistência (ÇALISKAN; CALLON, 2010). Portanto, uma representação de mercado produzida por uma revista ou um relatório setorial, por exemplo, decorre do agenciamento de um agregado de práticas representacionais cuja configuração torna possível que um ator (humano ou nãohumano) possa agir por outro (CALLON, 1986). Já sua condição de hegemonia estaria relacionada na forma com que o agenciamento assegura a reprodução de uma representação em detrimentos de outras. 
A relação das práticas representacionais (KJELLBERG; HELGESSON, 2006; 2007a) com agenciamentos sociotécnicos (ÇALISKAN; CALLON, 2010) hegemônicos ou alternativos incorre na produção de diferentes versões para um mesmo mercado. Esta possibilidade teórica está em consonância com a ontologia da teoria ator-rede segundo a qual a realidade produzida com e a partir de dimensões históricas, culturais e materiais é singular, porém múltiplas e não plurais (MOL, 1999). Dito de outra forma, o que se torna real é produto do relacionamento estabelecido, e que está provisoriamente estabilizado, entre as diversas práticas de entidades heterogêneas (atores humanos e não-humanos) situadas no tempo e espaço (LAW; URRY, 2004).

É possível identificar na literatura pesquisas empíricas orientadas pelo conceito de práticas representacionais. Ruiz (2013) mostra como objetos representacionais são mobilizados por profissionais de pesquisa de mercado para apresentar resultados a seus clientes. Em boa medida, as práticas desses profissionais lidam com tensões sobre como estabelecer as fronteiras de um dado mercado, quais atores e práticas merecem ser incluídos e se o trabalho pode ser resumido às descrições ou enfatizar oportunidades de negócio. Já Hagberg e Kjellberg (2015) exploraram como as representações de preço do mercado varejista de alimentos são produzidas e de que forma estão relacionadas com práticas de precificação e de mercado. Para Stigzelius (2018), consumidores são tidos como resultados de situadas práticas de mercado que possibilitam diferentes modos de engajamento. A investigação parte de como as representações de consumidores são articuladas por meio de práticas de mercado de forma a produzir sua versão politizada. Por fim, Ruiz e Kjellberg (2020) analisaram centenas de publicações online para investigar como emergem e são consolidados novos segmentos de mercado. Para os autores a prática de segmentação em si, quando estabilizada determinada categoria, é constituída por práticas representacionais.

No entanto, vale ressaltar que as pesquisas mencionadas acima não necessariamente promoveram esforços em explicar como as práticas representacionais contribuem para manutenção ou alteração de agenciamentos sociotécnicos de mercado. Para a presente pesquisa, as práticas representacionais permitem investigar a formação de mercados e as configurações dos agenciamentos à medida em que a representação é constituída por uma rede de agregados heterogêneos (humanos e não-humanos) que torna possível que um ator aja em nome de outro por meio de processos de translação (CALLON, 1986).

Existe uma ampla variedade de estratégias para condução de pesquisas sobre formação de mercados (LINDMAN, 2012; RUIZ, 2013; ROSCOE, 2015). Dentre elas, a perspectiva histórica merece destaque por oferecer diversas possibilidades de reconstituir e produzir 
conhecimento sobre o passado em momento presente, tendo o material de arquivo como importante fonte para compor de forma parcial ou integral os desenhos de pesquisa (DUREPOS; MILLS, 2011; BARROS et al., 2019). Como esta perspectiva será adotada para investigar como o agenciamento das práticas representacionais produziu versões no passado sobre o mercado de produtos orgânicos, a seção a seguir apresenta seus fundamentos a partir dos desenvolvimentos da área de estudos organizacionais e as justificativas que levaram à escolha pela vertente reorientacionista.

\section{A OPÇÃO POR UMA PERSPECTIVA HISTÓRICA REORIENTACIONISTA PARA OS ESTUDOS SOBRE FORMAÇÃO DE MERCADO}

Embora a adoção de métodos vinculados a perspectivas históricas na área de marketing tenha apresentado um relevante incremento nas últimas décadas (TADAJEWISKI; JONES, 2014; BALMER; BURGHAUSEN, 2019), no Brasil tal prática ainda parece pouco reconhecida (SAUERBRONN; FARIA, 2009; BOSCHI, 2018). O cenário muda quando observado o campo de estudos organizacionais (COSTA et al., 2010) e, de forma mais específica, na forma como são manuseados materiais de arquivo para produção de conhecimento científico (BARROS, 2016; COSTA; SILVA, 2017).

No âmbito dos estudos organizacionais, o papel da história na produção de conhecimento científico ganhou destaque com movimento que ficou conhecido como "virada histórica" na década de 1990 (BOOTH; ROWLINSON, 2006; COSTA; SILVA, 2019). Para Clark e Rowlinson (2004), este movimento exerceu impacto tanto sobre debates historiográficos quanto sobre teorias da história tornando ambíguo próprio termo, "história", uma vez que poderia estar associado tanto ao conjunto de ações humanas ocorridas no passado quanto à maneira como diferentes narrativas são produzidas sobre estas mesmas ações. Embora o movimento da "virada histórica" abrigasse diferentes abordagens, compartilha em comum, o entendimento de que o passado é constituído a partir de uma lógica processual, não sendo considerado somente como variável ou elemento de importância secundária para contextualização de fenômenos.

Mais do que entender o passado a partir de séries de eventos ocorridos, o que aponta a "virada histórica", particularmente em sua vertente reorientacionista (USDIKEN; KIESER, 2004), é que o passado consiste em um processo contínuo que envolve processos de contestação. Isso ajuda tanto a explicar a importância das dimensões de poder e de legitimidade em orientar as ações e discursos dos atores (GODFREY et al., 2016), como o fato de a produção de conhecimento sobre o passado em tempo presente implicar em diferentes versões para um 
mesmo período histórico (DUREPOS; MILLS, 2011; CORRIGAN, 2016). Essa abordagem baseada na narrativa se distancia da concepção funcionalista-positivista, tão comum no âmbito dos estudos organizacionais (FERREIRA, 2010). De forma específica, o distanciamento se refere à pretensa universalidade atribuída ao conhecimento científico, que desconsidera as peculiaridades históricas e institucionais de países com diferentes níveis de desenvolvimento, e à concepção de que o presente é um período descolado de seus precedentes históricos (BOOTH; ROWLINSON, 2006; WANDERLEY; BARROS, 2018).

A vertente reorientacionista acena para métodos alternativos de pesquisa e para abordagens que suscitem críticas e reflexões éticas (BOOTH; ROWLINSON, 2006). Isso ajuda a explicar por que pesquisas conduzidas sob esta corrente também encontram abrigo nos estudos críticos organizacionais (CLARK; ROWLINSON, 2004; WEATHERBEE, 2012). A adoção da postura crítica para produzir conhecimento sobre o passado viabilizou o surgimento de uma abordagem que está justamente assentada sobre os mesmos pressupostos dos Estudos Construtivistas de Mercado.

Durepos e Mills (2011) propõem utilizar a teoria ator-rede como método historiográfico ressaltando inclusive algumas lacunas presentes nesta tradição teórica: enquanto que originalmente o interesse recai sobre a forma com que as práticas de elementos heterogêneos (humanos e não humanos) produzem a realidade no momento em que agem, não há claros apontamentos sobre como essas práticas são historicamente constituídas ou como os pressupostos da teoria ator-rede poderiam ser utilizados para investigar o passado. Para os autores, os métodos historiográficos permitem a produção de conhecimento sobre o passado em tempo presente argumentando que o passado não pode ser empiricamente verificado uma vez que já ocorreu. Portanto, não se pode atribuir a ele status de uma ontologia realista ainda que sua existência esteja assegurada.

Sendo assim, o foco recai em mapear as associações dos atores que compõem a rede deste passado, operação que demanda do pesquisador uma postura crítica e reflexiva à medida em que é, ele próprio, parte integrante desta rede (DUREPOS; MILLS, 2011). Isto implica que a escolha do pesquisador em descrever uma dentre as múltiplas (não plurais) versões de um passado envolve dimensões de poder já que pode favorecer versões dominantes ou versões alternativas (MOL, 1999; DUREPOS; MILLS, 2011; CORRIGAN 2016). O acesso a essas versões do mercado do passado por meio de fontes de dados disponíveis em arquivos permitiria a identificação de práticas representacionais (KJELLBERG; HELGESSON, 2006; 2007a), da configuração dos agenciamentos sociotécnicos (ÇALISKAN; CALLON, 2010) e submeter as dimensões de poder e de ideologia ao escrutínio crítico. 
A aproximação entre o movimento da "virada histórica" nos estudos organizacionais e os estudos sobre formação de mercado em marketing que buscam produzir conhecimento a partir de fenômenos localizados no passado, pode acenar para promissoras linhas de pesquisa, a começar, pela superação da influente concepção de mercado, tanto em marketing (ARAUJO et al., 2010; RUIZ, 2013) quanto em estudos organizacionais (BARNEY; HESTERLY, 2004), baseada nos pressupostos da economia neoclássica, um paradigma reconhecidamente ahistórico (CLARK; ROWLINSON, 2004; GODFREY et al., 2016). O trabalho de Cochoy et al. (2018) é um exemplo da condução de problematizações da concepção dominante de mercado, já iniciadas na disciplina de marketing (ARAUJO et al., 2008), no âmbito dos estudos organizacionais que, por sua vez, reconhece que esse é um fenômeno que merece ser melhor explorado (AHRNE et al., 2014).

Da mesma forma, é possível perceber a influência de métodos históricos em trabalhos sobre formação de mercado na área de marketing (BURR, 2014) para investigar tanto fenômenos contemporâneos (KJELLBERG; OLSON, 2017) quanto fenômenos vinculados a períodos específicos de tempo (KJELLBERG; HELGESSON, 2007b; BURR, 2014; COCHOY, et al., 2018). Como a presente pesquisa se enquadra neste último caso, apresenta-se abaixo, no quadro 1, o objetivo, a fonte de dados e os métodos utilizados por pesquisas associadas aos Estudos Construtivistas de Mercado que adotaram uma perspectiva histórica.

Quadro 1. Estudos Construtivistas de Mercado que adotam perspectiva histórica.

\begin{tabular}{|c|c|c|c|}
\hline Autor & Objetivo & Fonte & Método \\
\hline $\begin{array}{l}\text { Cochoy et al. } \\
(2018)\end{array}$ & $\begin{array}{l}\text { Investigar como os preços são } \\
\text { registrados em diversos } \\
\text { dispositivos de mercado e como a } \\
\text { evolução das práticas e técnicas de } \\
\text { registros de preços exercem } \\
\text { impacto sobre a economia. }\end{array}$ & $\begin{array}{l}\text { Arquivos de revista setorial } \\
\text { no período de } 1922-1947 \text {. }\end{array}$ & $\begin{array}{l}\text { Abordagem etnográfica } \\
\text { adaptada a dados históricos } \\
\text { gráficos e técnicos com } \\
\text { abordagem } \\
\text { etnometodológica aos } \\
\text { registros de preço. }\end{array}$ \\
\hline $\begin{array}{l}\text { Geiger e } \\
\text { Finch }(2016)\end{array}$ & $\begin{array}{l}\text { Investigar o papel da regulação } \\
\text { através de uma investigação da } \\
\text { Comissão Europeia sobre os } \\
\text { processos de inovação no mercado } \\
\text { farmacêutico. }\end{array}$ & $\begin{array}{l}\text { Documentos públicos } \\
\text { produzidos pela Comissão } \\
\text { Europeia ao longo de uma } \\
\text { investigação sobre setor } \\
\text { farmacêutico no período de } \\
2008-2012 \text {. }\end{array}$ & Uso de narrativas \\
\hline $\begin{array}{l}\text { Hagberg } \\
(2016)\end{array}$ & $\begin{array}{l}\text { Explorar a dinâmica processual de } \\
\text { agenciamento através da análise } \\
\text { histórica das práticas que cercam } \\
\text { as sacolas de compra. }\end{array}$ & $\begin{array}{l}\text { Arquivos de uma revista } \\
\text { setorial entre os anos de } \\
\text { 1935-2013. }\end{array}$ & Estudo de caso \\
\hline $\begin{array}{l}\text { Araújo e } \\
\text { Kjellberg } \\
(2016)\end{array}$ & $\begin{array}{l}\text { Explorar os processos de } \\
\text { agenciamentos de mercados } \\
\text { através dos programas de } \\
\text { fidelidades de uma companhia de } \\
\text { aviação civil. }\end{array}$ & $\begin{array}{l}\text { Material de arquivo digital } \\
\text { abrangendo o período de } \\
\text { 1981-1991. }\end{array}$ & Estudo de caso histórico \\
\hline Burr (2014) & $\begin{array}{l}\text { Entender como atores de mercado } \\
\text { aprendem e respondem ao uso de } \\
\text { ambientes a partir da comparação }\end{array}$ & $\begin{array}{llr}\text { Acervo } & \text { de } & \text { bibliotecas } \\
\text { nacionais } & \text { para } & \text { consultar }\end{array}$ & $\begin{array}{l}\text { Análise } \\
\text { comparativa }\end{array}$ \\
\hline
\end{tabular}




\begin{tabular}{|l|l|l|l|}
\hline & $\begin{array}{l}\text { entre os mercados de bicicletas } \\
\text { americano e francês. }\end{array}$ & $\begin{array}{l}\text { revistas no período de } \\
1865-1914 .\end{array}$ & \\
\hline Kjellberg e & Explorar as associações entre a & Material de arquivo e atas & Estudo de caso histórico \\
Helgesson & forma específica com que trocas & de reunião de uma & \\
$(2007 b)$ & econômicas são organizadas e a & importante associação local & \\
& $\begin{array}{l}\text { constituição de objetos e agentes } \\
\text { de troca na introdução do }\end{array}$ & & \\
& no período de 1940-1950. & \\
& autosserviço no varejo sueco. & & \\
\hline
\end{tabular}

Fonte: Elaboração dos autores.

As pesquisas do quadro 1 repercutem a utilização de conceitos da teoria ator-rede para investigar a formação dos mercados em períodos específicos de tempo. Desta forma, buscam acessar o passado para produzir conhecimento sobre mercado em tempo presente. Em termos ontológicos, reconhecem a natureza sociomaterial de uma realidade sempre em movimento e, em termos epistemológicos, recorrem dentre outros, aos conceitos de translação e de agenciamento para observar as práticas dos atores humanos e não-humanos. Ainda assim, Durepos e Mills (2011) alertaram que a trilha de pesquisa proposta por Callon (1999), que possui influência marcante sobre os estudos construtivistas de mercado (ARAUJO et al., 2008; ARAUJO; KJELLBERG, 2009), falha em explicar como a realidade histórica é constituída, ou dito de outra forma, como conhecimento histórico sobre formação de mercado poderia ser produzido.

De fato, as pesquisas elencadas no quadro 1 também são pouco elucidativas sobre essa mesma questão. Neste sentido, a aproximação com o movimento de "virada histórica", principalmente sua vertente mais crítica (BOOTH; ROWLINSON, 2006; MILLS et al., 2016), não só ajudaria a preencher essa lacuna como incluir dimensões sociais e políticas que cercam e constituem as versões do passado.

Apresentadas as noções de agenciamento sociotécnico e de práticas representacionais bem como a forma com que a vertente reorientacionista da "virada histórica", representada na proposta de Durepos e Mills (2011), pode contribuir para acessar versões de mercado no passado, a seção a seguir discorre sobre o percurso metodológico adotado.

\section{PERCURSO METODOLÓGICO}

A abordagem escolhida para a presente pesquisa consiste em um estudo de caso histórico (ARAUJO; KJELLBERG, 2016) de perspectiva longitudinal (VIEIRA, 2004), tendo como fonte de dados a revista A Lavoura editada pela Sociedade Nacional de Agricultura (SNA). Fundada em 1897, a SNA é uma instituição vinculada aos interesses do agronegócio (PINTON; 
YANNICK, 2019) cuja atuação abrange a difusão de conhecimentos técnicos e educacionais. Situada na cidade do Rio de Janeiro possui um campus de aproximadamente 144.000 metros quadrados e oferece cursos de graduação, pós-graduação e de extensão em parceria com outras instituições de ensino (SNA, 2019).

O início da publicação da revista A Lavoura coincide com o ano de fundação da SNA e sua distribuição alcança centros de pesquisa, universidades, sindicatos, associações rurais, entidades de representação profissional, empresas do agronegócio e bibliotecas do Brasil e exterior. Trata-se de uma publicação que abriga reportagens tanto técnicas quanto informativas, voltadas para as atividades que compõem a cadeia de produção agrícola (A Lavoura, 2019).

O arquivo consultado está localizado na unidade da SNA do centro da cidade do Rio de Janeiro e franqueado ao público. Originalmente, o objetivo deste projeto era de investigar as repercussões produzidas pela instituição do marco legal de produtos orgânicos no Brasil com a publicação da lei 10.831 de 2003 (BRASIL, 2003) e da sua respectiva regulamentação, que veio a ocorrer com o decreto 6.323 publicado em 2007 (BRASIL, 2007). Esperava-se encontrar na revista A Lavoura linhas editoriais, reportagens especiais e entrevistas com especialistas capazes de revelar sobre como o agenciamento das práticas representacionais (KJELBERG; HELGESSON, 2006; 2007a) produziu versões do mercado de produtos orgânicos. A revista, portanto, é entendida como entidade que representa e age por diversos atores (humanos e nãohumanos) à medida que produz e faz circular determinadas versões de mercado. Dentre as indagações iniciais que orientaram a pesquisa destacam-se: Quem eram esses atores? Quais foram incluídos/excluídos ao longo do tempo? Como que uma nova configuração de atores, estabelecida a partir de práticas representacionais, altera agenciamentos implicando no enfraquecimento ou na promoção de novas versões do mercado de produtos orgânicos?

A instituição do marco legal suscitava a constituição de um novo agenciamento sociotécnico no mercado de produtos orgânicos uma vez que, até tal realização, não haviam quaisquer esforços de regulamentação semelhante (FONSECA, 2009). Portanto, a expectativa inicial consistia em identificar nas edições da revista A Lavoura, versões de mercado em períodos anteriores e posteriores à publicação da lei 10.831. Contudo, a pesquisa in loco apontou para novos desdobramentos à medida que um dos autores se relacionava cada vez mais com o material coletado. Notou-se, sobretudo, mudanças claras (e até mesmo rupturas bruscas) na forma como o mercado em questão era retratado.

Em consonância com uma orientação indutiva (YIN, 2016), as impressões iniciais deste pesquisador sobre a existência de diferentes versões do mercado de produtos orgânicos, não necessariamente relacionadas com a instituição do marco legal, justificaram a decisão de 
organizar por períodos temporais (HOLLANDER et al., 2005) cada versão identificada. De fato, a decisão foi ratificada após as discussões com a coautora do trabalho que, tiveram como base, leituras flutuantes do material coletado.

O corpus da pesquisa (BAUER; GASKELL, 2002), portanto, foi formado pelas edições publicadas no período de 1990-2007. À princípio foram observadas as temáticas concernentes ao mercado de produtos orgânicos nos títulos das reportagens. As menções mais claras foram identificadas a partir do ano 2000. Nos anos anteriores, a temática figurava de forma marginal em reportagens que abordavam assuntos correlatos e com pouca menção direta, se tornando cada vez mais escassa, nas edições publicadas no início dos anos 1990. Já entre 2000 a 2002, a temática foi identificada em clara associação com a agricultura orgânica. A partir de 2003 até o final do ano de 2007, o foco passou a ser sobre os aspectos mercadológicos dos produtos orgânicos. Importante ressaltar que este último período apresentou maior regularidade e volume de reportagens em relação aos demais.

De acordo com a vertente reorientacionista da "virada histórica", materializada na proposta de Durepos e Mills (2011), as descrições do passado não denotam uma realidade estável, concreta, única e predeterminada. Para os autores o passado é constituído por atores heterogêneos cujos aspectos sociais e políticos de suas práticas incorrem na estabilização de uma configuração de rede que permite a disseminação de uma certa versão do passado em detrimento de outras. É essa versão estabilizada que permite a produção de conhecimento sobre o passado e o que torna mais prática a sua identificação pelo pesquisador.

$\mathrm{O}$ acesso às versões do passado do mercado de produtos orgânicos viabilizado pelas reportagens permitiu que narrativas fossem produzidas pelos pesquisadores a partir das descrições e do mapeamento das associações entre os atores, considerando as dimensões sociais e políticas das práticas representacionais, e a forma como contribuem para configuração de agenciamentos sociotécnicos. A figura abaixo, apresenta a proposta teórica desenvolvida para a operacionalização da pesquisa.

Figura 1. Proposta teórica para operacionalização da pesquisa. 


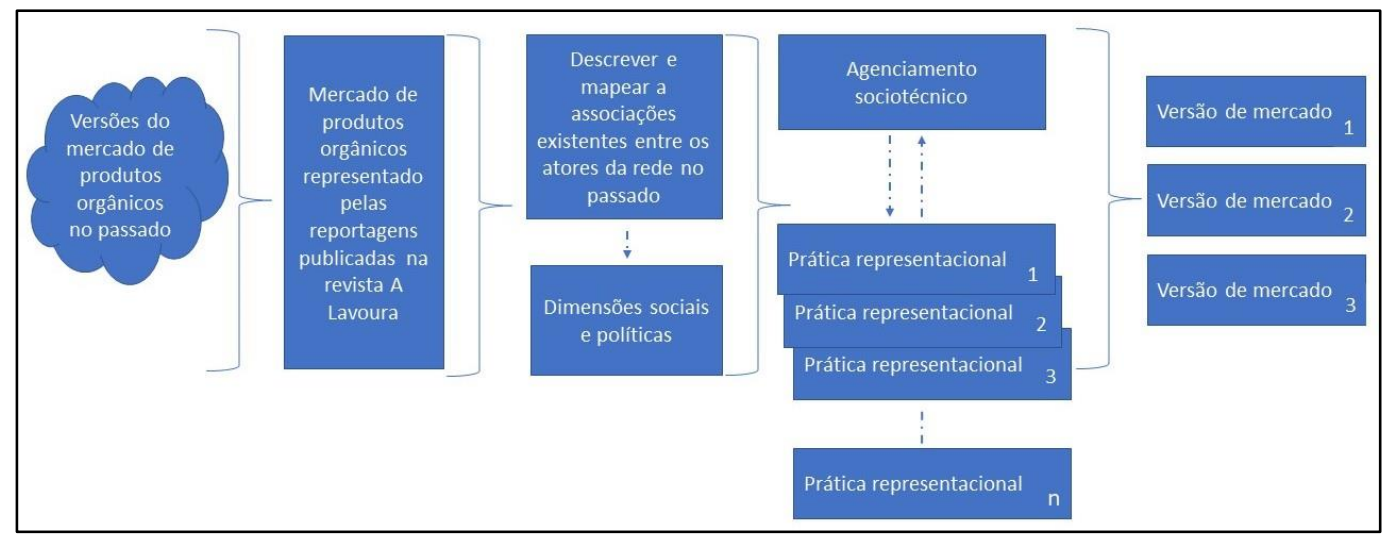

Fonte: Elaborado pelos autores.

As reportagens selecionadas das edições foram fotografadas com recursos básicos do telefone celular, procedimento consentido pela responsável da SNA pelo acervo posto à disposição. Ao todo 196 páginas foram fotografadas. Embora possam ser apontadas limitações por recorrer somente a uma fonte de dados, tal procedimento se justifica uma vez que seguir um único ator (a revista) ao longo do processo de desenvolvimento histórico (COCHOY, 2010; HAGBERG, 2016) permitiu a identificação de diferentes versões do mercado de produtos orgânicos cujas descrições, mais do que descrever, contribuíram para que essas versões da realidade se "tornassem reais" (CALLON, 1998; LAW; URRY, 2004).

Dispostas as reportagens em ordem cronológica, o processo de descrição e de análise foi composto por duas etapas. A primeira etapa confirmou as suspeitas registradas nas notas de campo quando do momento da coleta: existem, ao longo do período considerado, diferentes práticas representacionais que integram específicos agenciamentos sociotécnicos. Nesta etapa, os dados foram codificados e categorizados em função de cada versão de mercado identificada. A segunda rodada foi necessária para detalhar as descrições e produzir as narrativas. Em cada reportagem não somente o texto foi considerado, mas também as figuras e fotos que a compunha (COCHOY et al., 2018). Uma vez mapeados os atores, procedeu-se esforços em reconstituir seus movimentos e a forma com que estavam relacionados.

\section{APRESENTAÇÃO DAS VERSÕES DE MERCADO}

\subsection{VERSÃO I (1990-1999): UMA ALTERNATIVA À PRODUÇÃO AGROALIMENTAR CONVENCIONAL}


A partir das noções convencionais de indústria, o mercado de agrotóxicos e o mercado de produtos orgânicos poderiam ser considerados distintos. Contudo, no lastro dos Estudos Construtivistas de Mercado, pode-se argumentar que as fronteiras entre eles estabelecem pontos de contato capazes de produzir efeitos sobre suas configurações. Kjellberg e Olson (2017), por exemplo, já verificaram tal fenômeno em mercados regulados. Em boa medida, as reportagens desse período se referiram mais às agriculturas alternativas, do que ao mercado de produtos orgânicos propriamente dito, e estabeleciam uma espécie de contraposição ao sistema de produção agroalimentar convencional, baseado no uso de agrotóxicos.

A maior parte das reportagens da revista A Lavoura sobre agrotóxicos e que traziam alguma relação com a temática dos produtos orgânicos foi publicada na seção "Extensão Rural", no período de 1990-1999. No início deste período, as matérias variavam desde os riscos de intoxicação humana e de animais até as implicações sobre o meio ambiente. Os riscos à saúde daqueles que diretamente manuseavam os agrotóxicos foram relatados, como no caso das adubadeiras

[...] mulheres e crianças que trabalham nos canaviais da Paraíba, estão adoecendo em razão do contato direto com adubos químicos e herbicidas. Sem equipamentos de proteção e sem opção de trabalho, as adubadeiras submetem-se à tarefa de colaborar com o marido ou até mesmo de sustentar a família (A LAVOURA, 1991, p. 21).

No mesmo ano em que o trecho sobre os riscos do trabalho das adubadeiras foi publicado, reportagens da seção "Controle Biológico" já apontavam para agriculturas alternativas como opções à produção convencional de alimentos. Neste caso, os efeitos provocados pelo uso de agrotóxicos já não eram retratados somente em função dos riscos à saúde dos trabalhadores, mas também do seu impacto sobre consumidores, meio ambiente e economia.

A produtividade da agricultura brasileira, tendo como base o uso de agrotóxicos, pode ser perigosa demais para o meio ambiente, muito arriscada para o consumidor, e muito problemática para o agricultor [...] Houve diminuição da competitividade dos produtos agrícolas brasileiros no mercado mundial, porque há uma exigência cada vez maior por alimentos sadios, não contaminados por agrotóxicos (A LAVOURA, 1991, p. 44).

Ainda assim, mesmo com o retrato de iniciativas como a elaboração de hortas domésticas orientada pela agrobiologia, havia o entendimento de que a utilização de produtos químicos era um mal necessário (A LAVOURA, 1995, p. 29), acentuando novamente os riscos sobre manuseio e doenças associadas. 
"Fungicidas, inseticidas e os falsos defensivos agrícolas são produtos altamente venenosos para o homem, daí as precauções que devem ser tomadas. A agrobiologia vai aos poucos assumindo papel preponderante, substituindo e minimizando os efeitos danosos na saúde do homem. Mas enquanto a convivência com os produtos químicos (mal ainda necessários) não for banida de vez (?), seus usuários devem se prevenir dos efeitos deletérios" (A LAVOURA, 1995, p. 29).

A reportagem de onde foram retirados os trechos acima foi publicada na seção "Horticultura" e contém cinco fotos que retratam o cultivo de hortas e os tipos de pragas que assolam certos cultivares. É justamente nesse último caso que a agrobiologia reconhece o uso de produtos químicos quando não for possível um tratamento de controle baseado em recursos encontrados na própria natureza.

No final da década de 1990, registros puderam ser identificados quanto à preocupação do poder público com o uso indiscriminado de agrotóxicos (A LAVOURA, 1998) e com o não cumprimento da lei que regulamenta o uso e a comercialização (A LAVOURA, 1999), a Lei de Agrotóxicos de $n^{\circ}$ 7.802, publicada em 1989 (BRASIL, 1989). Esses dois registros foram encontrados na seção de "Extensão Rural" sob o formato de pequenos textos que compartilhavam espaço com outras temáticas que tinham maior destaque de página.

\footnotetext{
O estado do Rio de Janeiro aprovou a Lei 801/84 e o Decreto 7.666 de 23 de outubro de 1984, criando a Comissão Estadual de Controle de Agrotóxicos e Biocidas CECAB. Os estados do Rio Grande do Sul e do Paraná foram os primeiros a iniciar os estudos e reação ao uso indiscriminado dos agrotóxicos, pleiteando a criação do Receituário Agronômico para disciplinar a venda e o uso desses produtos [...] Em 1989 foi sancionada a Lei 7.802 [...] dando-se assim base legal para a atuação de estados na questão. Lamentavelmente a CECAB foi desativada, o controle de agrotóxicos sofreu retração [...] (A LAVOURA, 1998, p.34).
}

Destacava-se ainda na época, que os agrotóxicos comercializados no Brasil foram proibidos nos países que os produziam pela suspeita de possuírem "substâncias cancerígenas e poluírem o meio ambiente" (A LAVOURA, 1999, p. 32). Mesmo no final da década de 1990, o uso elevado de defensivos agrícolas ainda constituía um grande obstáculo para as exportações brasileiras, vide, por exemplo, o campo da fruticultura (A LAVOURA, 1999, p. 19). Para lidar com esse e outros obstáculos, a Apex (Agência Brasileira de Promoção de Exportações e Investimentos) e o Governo Federal, com especial destaque para a atuação do Ministério da Agricultura, realizaram esforços em campanhas de marketing para produção brasileira. Importante frisar que o trecho abaixo, escolhido para representar os desdobramentos econômicos da produção baseada em agrotóxicos, é proveniente de uma reportagem publicada na seção "Agronegócio" 
O calcanhar de Aquiles das exportações de frutas brasileiras é o controle de pragas e doenças que atrapalham a produção de fruteiras como manga, melão e papaia. As barreiras já não são mais econômicas e sim de ordem fitossanitária, usadas pelos grandes mercados internacionais [...] A meta do Ministério na adoção do modelo integrado de produção é diminuir gradativamente o uso de defensivos agrícolas na produção das frutas (A LAVOURA, 1999, p. 19).

As restrições comerciais impostas sobre a exportação de produtos agroalimentares brasileiros devido ao uso indiscriminado de agrotóxicos, estimulava a busca por outras alternativas de produção economicamente viáveis. Porém, no final da década o conteúdo sobre agrotóxicos ocupava espaço cada vez mais restrito na revista. Em sua maioria, não constituía assunto principal, complementando de forma marginal reportagens sobre outras temáticas e retratado com pouca utilização de imagens. As exceções eram as curtas notas em seções específicas. O que foi possível perceber, é que a temática dos agrotóxicos acabou por encontrar abrigo nas contextualizações de um novo tipo de agricultura: a agricultura orgânica.

\subsection{VERSÃO II (2000-2001): UMA AGRICULTURA ORGÂNICA TECNICAMENTE VIÁVEL}

Apesar de essa seção temática constituir um período relativamente curto, foi possível observar a existência de novos conteúdos específicos sobre a agricultura orgânica e práticas representacionais distintas em relação ao período anterior. A guinada à agricultura orgânica teve influência marcante do Informativo do Centro Nacional de Pesquisa de Agrobiologia que foi publicado na Revista A Lavoura, sob o formato de encarte, nos anos 1998-2002. O conteúdo do informativo decorria em grande parte, de pesquisas realizadas pela Empresa Brasileira de Pesquisa Agropecuária, a Embrapa, e a partir de 2000, começou a dar maior destaque para a agricultura orgânica.

Chamou atenção o fato de a Embrapa ter apresentado, em uma das edições, uma definição de mercado relativamente distinta daquela comumente encontrada em marketing. Ao contrário de retratar mercado tão somente como espaço de encontro entre consumidores e produtores, a referida definição possui natureza muito mais plural conforme observado abaixo

Reconhecendo a todos o direito básico de acesso a suas tecnologias e conhecimento, a Embrapa definiu como mercado qualquer grupo humano, nacional ou internacional, público ou privado, cujos problemas ou interesses possam ser ajudados pelas tecnologias que desenvolve. Isto inclui desde as comunidades indígenas até corporações multinacionais, passando por pequenos produtores e órgãos públicos (A LAVOURA, 1998, p. 44). 
Além do Boletim da Embrapa, emergiram no início dos anos 2000 novos espaços específicos na revista para discussões sobre produtos orgânicos: as seções de "Agricultura Orgânica" e de "Agroecologia". Neste período, e em decorrência do que já foi exposto na seção anterior, os dados sugeriram uma maior polarização entre os sistemas de produção de alimentos orgânicos e a agricultura convencional

O uso indiscriminado de agrotóxico tem levado à contaminação dos trabalhadores
rurais e do agroecossistema em níveis intoleráveis de risco, além de contribuir
significativamente para o aumento do custo de produção das lavouras. Como forma
de reação a essa situação vigente tem-se verificado, em todo o país, uma crescente
busca de técnicas que utilizem insumos e defensivos alternativos (A LAVOURA,
2000 , p. 44).

De forma geral, as matérias publicadas nas seções de "Agricultura Orgânica" e de "Agroecologia" versavam sobre técnicas de produção de produto orgânico entendido como "aquele alimento cultivado sem o uso de agrotóxicos e adubos químicos" (A LAVOURA, 2000b, p. 44). Predominavam artigos de natureza técnica e científica com fotos de pesquisadores, agricultores, estudantes, produtos, dispositivos e sistemas de produção (como estufas e iscas para insetos). $\mathrm{O}$ manejo do solo, a produtividade, a adubação e o controle de doenças e pragas figuravam entre os principais conteúdos das reportagens publicadas nestas seções. O trecho abaixo, publicado na seção de "Agricultura Orgânica", revela não somente uma crítica ao modelo convencional de produção de alimentos baseado na chamada "Revolução Verde", mas também, uma dimensão econômica nem sempre favorável aos produtores vinculados a este sistema de produção.

\begin{abstract}
A revolução verde que pretendia acabar com a fome do mundo, recomendando o plantio de sementes melhoradas, o uso intensivo de fertilizantes químicos para corrigir as deficiências do solo e controle de pragas e doenças com o uso de agrotóxicos, trouxe uma série de problemas. Os exemplos são a multiplicação e desenvolvimento de resistência a produtos pelos organismos prejudiciais às lavouras, sérios distúrbios ecológicos como a contaminação da água, do solo, dos alimentos, e eliminação de inimigos naturais. Além disso, a revolução verde não conseguiu aumento significativo da produção. Pois, como o custo de produção se tornou proibitivo, reduziu demais o lucro do agricultor, tendo, em alguns casos, tornado suas atividades economicamente inviáveis (A LAVOURA, 2000c, p. 18).
\end{abstract}

Ressalta-se que não fica claro quem é o agricultor penalizado: se é o pequeno agricultor familiar ou o agricultor empresário já capitalizado. Em parte, isso pode ser explicado pelo foco das reportagens sobre aspectos produtivos das práticas de produção orgânica: manejo, adubação, controle de pragas e doença e o que cultivar na propriedade (A LAVOURA, 2000c, p. 119). No mesmo sentido, também ajuda a explicar por que as empresas públicas de pesquisa, 
como a Embrapa e a Pesagro, empresa de pesquisa agropecuária do estado do Rio de Janeiro, tinham espaço assegurado para divulgação de resultados como mostra o trecho extraído de uma reportagem da seção de "Agroecologia".

\begin{abstract}
A Estação Experimental de Itaguaí da Pesagro-Rio, desenvolveu um sistema de cultivo protegido do tomateiro, que utiliza caldas alternativas e outros insumos orgânicos, além da estufa rústica, que apresenta resultados promissores em termos de produção e sanidade. A estufa tem as seguintes características [...] (A LAVOURA, 2000d, p. 44).
\end{abstract}

Em 2001, o boletim informativo da Embrapa publicou uma matéria sobre a certificação orgânica no Brasil que, dentre os diversos atores mencionados, constava a Associação de Agricultores Biológicos do Estado do Rio de Janeiro, a ABIO (A LAVOURA, 2001, p. 46), organização reconhecida por sua atuação no contexto da agricultura orgânica. A ABIO figurou entre os atores que participaram das discussões sobre a regulamentação do mercado de produtos orgânicos e com a instituição do marco legal, por meio da lei 10.831 de 2003 e do decreto 6.323 de 2007, se tornou referência e um dos principais organismos de certificação do estado do Rio de Janeiro em uma das modalidades previstas em lei: o Sistema Participativo de Garantia (FONSECA, 2009). Assim como a ABIO, existiam outros organismos de certificação com atuação anterior à criação do marco legal que também contribuíram para a formação de um mercado cujo potencial era retratado pelo crescimento da agricultura orgânica e dos espaços de comercialização no Brasil (A LAVOURA, 2001, p. 47).

O ano de 2001 foi o último que abrigou as publicações do Boletim da Embrapa. Ainda no mesmo ano foi possível identificar uma reportagem relacionada à agricultura urbana que retrata a atuação de ONGs, empresas de pesquisa e universidades em comunidades do município do Rio de Janeiro. A reportagem é ilustrada por duas fotos que capturam a interação entre extensionistas e sociedade civil

\footnotetext{
Políticas públicas voltadas para o incentivo e a implementação da agricultura urbana podem favorecer e promover o desenvolvimento local das periferias de grandes cidades. Além disso, através do redirecionamento dos objetivos da comunidade, com ações participativas em todos os processos de desenvolvimento, é possível criar alternativas de vida saudável para jovens e crianças principalmente. A produção de alimentos de alta qualidade nutricional e sem agrotóxicos, desenvolvidos a um custo relativamente baixo, podem contribuir para melhorar a qualidade de vida e a receita familiar (A LAVOURA, 2001, p. 49).
}

A configuração dos diversos atores identificados nesta seção sofre considerável mudança na seção seguinte que revela uma nova virada das reportagens publicadas na revista A Lavoura. O foco deste novo período recai sobre os aspectos mercadológicos dos produtos orgânicos. 


\subsection{VERSÃO III (2002-2007): UMA CONCEPÇÃO EMPRESARIAL SOBRE O MERCADO DE PRODUTOS ORGÂNICOS}

Se por um lado houve a extinção das edições do Boletim da Embrapa, por outro, a emergência das seções de "Agronegócios" e de "Biotecnologia" contribuiu para a consolidação de uma visão mais empresarial sobre as práticas de agricultura orgânica. Essa guinada também foi percebida nas matérias especiais sobre o aniversário da SNA cuja cobertura envolvia a organização de seminários temáticos marcados pela presença de autoridades governamentais, de pesquisadores e de organizações privadas e do terceiro setor, conforme confirmam as legendas dos registros fotográficos.

\footnotetext{
Durante o primeiro dia do seminário, foi apresentado o projeto BioFach-Brasil, cujo objetivo é desenvolver o mercado orgânico brasileiro. Maria Beatriz Martins Costa, diretora-executiva do projeto, aproveitou para apresentar o Planeta Orgânico, que reúne na Internet diversos segmentos do setor. Houve ainda uma pequena mostra dos seminários BioFach promovidos em vários Estados brasileiros, com o propósito de divulgar os orgânicos e conscientizar os consumidores para a importância destes produtos, a fim aumentar a demanda (A LAVOURA, 2002, p. 7).
}

A BioFach, com sede na Alemanha, é retratada como uma importante feira internacional de produtos orgânicos e ponto de referência para exportações e desenvolvimento de negócios. Pesquisas já apontaram que essas feiras proporcionam a disseminação e reprodução de práticas representacionais (RINALLO; GOLFETTO, 2006; MEDEIROS et al., 2014) que, dependendo do agenciamento produzido, podem implicar na forma com que um mercado é retratado. Se entendido que o mercado de produtos orgânicos possui potencial de negócios a ser explorado, a apresentação na BioFach, por exemplo, de tendências de lançamento de novos produtos ou de projeções de crescimento baseadas em valores econômicos, ajuda a consolidar (pelo menos momentaneamente) esta versão específica de mercado. São esses processos de translação que fazem com que essa versão de mercado circule e alcance atores como a revista A Lavoura que, por sua vez, a reforça com a publicação em suas reportagens.

Adicionalmente o consumidor foi apontado nesse mesmo período não somente pelas reportagens da seção de "Agronegócios e Biotecnologia", mas também por aquelas publicadas na incipiente seção de "Casos de Sucesso", como um importante ator capaz de influenciar os rumos futuros do mercado de produtos orgânicos. Ao mesmo tempo, questões relacionadas à gestão e comercialização também começavam a ocupar espaços nas reportagens publicadas na 
seção de "Agricultura Orgânica", caracterizada nos períodos anteriores por privilegiar as práticas de agricultura, como mostra o trecho a seguir

\begin{abstract}
Apesar do incremento na procura de produtos orgânicos por parte dos grandes centros de consumo, há dificuldades do produtor na comercialização pois, embora o custo da produção seja mais baixo, o produto chega ao consumidor a um valor bem mais elevado. O mercado praticado não é justo, visto que o produtor não é bem remunerado e a sua margem de lucro fica igual ao convencional (A LAVOURA, 2003a, p.44).
\end{abstract}

À medida que a perspectiva empresarial se tornava cada vez mais presente nas reportagens da revista, os contornos do mercado de produtos orgânicos reforçavam as oportunidades de negócios sendo retratado basicamente, como um nicho do agronegócio brasileiro a ser explorado. Porém, o acesso às oportunidades destacadas tende a ser mais difícil para o "produtor comum", na visão de um empresário que participou de uma reportagem da seção "Casos de Sucesso"

\begin{abstract}
Fomos obrigados a realizar uma grande reestruturação, em termos empresariais e de produtividade, para atendermos ao crescimento da demanda. Aumentamos bastante o nosso investimento, reformando e ampliando o galpão, com a compra de caixotes plásticos, e com a instalação de câmaras frias de despacho e recebimento umidificadas [...]. Infelizmente, o produtor comum, que não dispõe dessa tecnologia toda, é obrigado a deixar a sua colheita mal acondicionada em caixotes de madeira, e atravessadores a comercializam. É uma situação que sacrifica bastante o agricultor e ainda gera muitas perdas (A LAVOURA, 2003b, p. 49).
\end{abstract}

A orientação das reportagens para os aspectos mercadológicos também revelava o próprio posicionamento da SNA. Concorre para sustentar tal constatação o fato de a instituição ter lançado em 2004 um programa de incubadora de agronegócios, "a primeira no país voltada ao mercado de orgânicos" (A LAVOURA, 2004, p. 9), e que cujo intento era "ajudar as empresas a deslancharem seus projetos e crescer, de modo que possam se transformar em empresas grandes e competitivas" (A LAVOURA, 2004, p. 9).

Esta iniciativa ainda contava com apoio de outras instituições. O trecho abaixo foi extraído de uma reportagem sobre a cobertura do evento de lançamento do programa de incubadora publicada na seção "SNA 107 Anos". Consta nele, a participação de um executivo do Sebrae, organização reconhecida por fomentar o empreendedorismo, que produziu uma representação do mercado de produtos orgânicos muito próxima daquela disseminada pela SNA

Aproveitando a ocasião, falou sobre a importância dos produtos orgânicos registrando o aumento de empresas neste setor que, segundo ele tem como meta "produzir bem, com responsabilidade social, sem deixar de lado as questões relacionadas ao meio ambiente". E complementou: "É preciso vender produtos de forma diferenciada, por um preço melhor [...]" (A LAVOURA, 2004, p. 9). 
As fotos deste período retratavam o funcionamento dos sistemas de produção e as embalagens dos produtos fornecidos pelas empresas mencionadas nas seções de "Casos de Sucesso" e "Agronegócios e Biotecnologia". No caso das embalagens, o produto orgânico, por vezes, era considerado um típico produto de alto valor agregado, cuja gestão em nada se diferiria, do que é apregoado convencionalmente pela disciplina de marketing (KOTLER; KELLER, 2006).

O produto, visto através da transparência das embalagens, deve "gritar": sou fresco, sou gostoso, fui feito com carinho e sob restritas normas de qualidade para você". Embalagens coloridas e atrativas levam esse recado aos consumidores. Os preços dos produtos orgânicos acabam sendo mais altos do que o dos produtos convencionais, e os consumidores, mais exigentes, devem ser tratados de maneira distinta (A LAVOURA, 2005, p. 23).

Importante ressaltar que uma reportagem específica publicada em uma seção denominada “Especial Orgânicos" chamou a atenção por causa do seu título: "produtos orgânicos: produção sustentável com segurança alimentar”. Em um momento em que se tinha identificado uma virada nas publicações em direção aos aspectos mercadológicos dos produtos orgânicos, o conceito de segurança alimentar parecia destoar. Este conceito implica em pensar o alimento produzido em qualidade e quantidade suficientes para garantir a sobrevivência humana, o que ajuda a explicar por que comumente está relacionado com o desenvolvimento de políticas públicas de combate à fome (PINTON; YANNICK, 2019).

No entanto, não foi a partir desta concepção que a segurança alimentar foi mencionada. A referência que se fez na reportagem estava mais próxima de uma dimensão de confiança dos consumidores em relação aos atributos dos produtos orgânicos, conforme mostra o destaque abaixo

O mercado de produtos orgânicos vem aumentando significativamente nos últimos anos com estimativa de negócios ao redor de 30 bilhões de dólares para 2005. Isto é resultado da exigência crescente dos consumidores por produtos que ofereçam segurança alimentar e que sejam produzidos com mínima agressão ao meio ambiente (A LAVOURA, 2005. p. 32).

O restante da reportagem prossegue com a ênfase no potencial deste mercado. Tal incômodo sentido pelos autores ao se deparar com o uso, pelo menos incompleto, do conceito de segurança alimentar, ilustra os diferentes enquadramentos que o mercado de produtos orgânicos pode ter. Ainda nesta seção especial, há a menção acerca da legislação brasileira sendo qualificada como a "mais democrática do mundo" (A LAVOURA, 2005, p.35), em 
virtude da existência em lei de diferentes mecanismos de garantia da qualidade. Contudo, o processo de discussão sobre a regulamentação do mercado de orgânicos tinha sua linha de argumentação reduzida às dimensões de produto de forma a viabilizar um "processo de comunicação ao mercado e aos consumidores da realidade ou veracidade de um fato" (A LAVOURA, 2006, p. 35). Neste sentido, as atividades de marketing poderiam se valer da certificação como dispositivo que "diferencia e valoriza os produtos, regulando e facilitando a sua venda" (A LAVOURA, 2006, p. 35).

\section{AGENCIAMENTO DE PRÁTICAS REPRESENTACIONAIS NAS TRÊS VERSÕES DE MERCADO}

A seção anterior teve como objetivo identificar e descrever as práticas representacionais presentes nas reportagens publicadas na revista A Lavoura no período de 1990-2007. Analisando textos e fotos, percebeu-se que as associações que tais práticas estabeleciam com diferentes atores constituíram distintos agenciamentos sociotécnicos que, estabilizados por determinados períodos de tempo, produziram diferentes versões do mercado de produtos orgânicos no passado.

Essas oscilações do passado não só permitiram contar a história recente deste mercado como constatar os movimentos de framing e de overflowing (CALLON, 1998) entre as versões que contribuíram para sua formação. A figura 2 abaixo, ilustra justamente a relação desses movimentos com as três versões do mercado de produtos orgânicos produzidas em decorrência de diferentes configurações de agenciamento das práticas representacionais. A comprovação da existência de diferentes versões de mercado no passado encontra respaldo na perspectiva ontológica adotada, segundo a qual a realidade é múltipla e fruto de uma construção sociomaterial (MOL, 1999).

Figura 2. Versões de mercado e movimentos de framing e de overflowing 


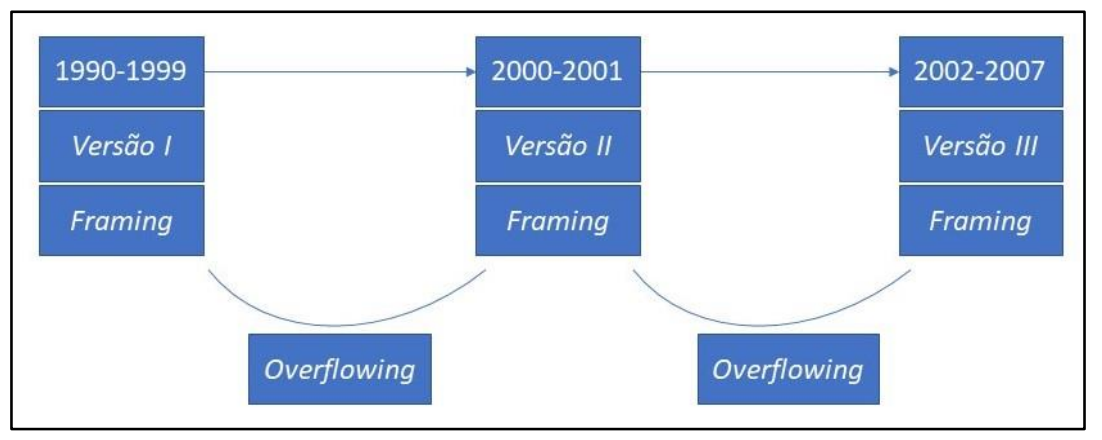

Fonte: Elaborado pelos autores.

De forma geral, as práticas representacionais observadas nas reportagens constituíram, em cada período, uma espécie de trama formada pela associação entre atores que, quando estabilizada, produziu versões da realidade e estabeleceu enquadramentos sobre quem dela faz parte. A substituição da ideia de trama, ou de rede, pelo conceito de agenciamento, permite o entendimento de que estas práticas foram agenciadas, ou seja, postas em ação para produzir versões de mercado. Dito de outra forma, é o nexo de relações entre as representações de atores que, quando assegurado, faz o todo agir e produzir uma representação hegemônica de mercado.

Sendo assim, a Versão I apresentou uma configuração específica de agenciamento das práticas representacionais de atores humanos e não humanos capaz de manter estáveis as associações estabelecidas. Ocorreu que ao final do seu período, outros atores emergiram e a sua inclusão, provocou instabilidade no enquadramento até então existente. Trata-se do movimento de overflowing, que neste caso, estendeu o enquadramento a atores que eram afetados, que tinham interesse em participar ou de serem reconhecidos no processo de formação do mercado de produtos orgânicos. No início do período da Versão II, a inclusão e/ou distribuição de relevância entre os atores pelas práticas representacionais, modificou a configuração do agenciamento que, ao estabelecer e estabilizar uma nova relação de associações, o fez agir de outra forma, com um novo enquadramento e, por conseguinte, com uma nova versão de mercado.

Já o surgimento e a estabilização da Versão III teve sentido contrário. O enquadramento decorrente dessa versão implicou no deslocamento para a margem de atores que historicamente fizeram parte das representações deste mercado. Isso porque os processos de translação que passariam a forjar as associações entre os atores estavam baseados em bases de conhecimento igualmente exclusivas quando comparadas com as bases das duas primeiras versões de mercado. Desta forma, a natureza política e social que encerra a produção das versões de mercado apresenta dinâmicas de inclusão e de marginalização em decorrência do agenciamento das práticas representacionais. Ao pensar que as versões de mercado identificadas 
correspondem a narrativas e representações hegemônicas, pode-se dizer que, à medida que as reportagens circulam sobre as diversas esferas da sociedade, acabam por reproduzir a própria condição de marginalidade de determinados atores.

As práticas representacionais do mercado de produtos orgânicos agenciadas na Versão I evidenciaram associações entre atores (humanos e não humanos) dentre os quais podem ser mencionados: produtores rurais, consumidores, hortas, pragas, agrotóxicos, leis e órgãos governamentais. Foi possível perceber que em alguns casos as associações foram reforçadas por processos de translação com base em conhecimentos como economia, ecologia e agrobiologia quando questões como competitividade, impactos ambientais e controle biológico eram respectivamente mencionadas. A estabilização dessas associações entre 1990-1999 produziu uma representação do mercado de orgânicos que ajudou a disseminar a narrativa de que a agricultura alternativa emergiu em contraposição à agricultura convencional, principalmente, pelo reconhecimento dos efeitos nocivos vinculados aos agrotóxicos sobre consumidores, meio ambiente e agricultores.

A segunda versão indicou justamente o enfraquecimento das associações entre os atores do agenciamento identificado na primeira versão e, consequentemente, do enquadramento que até então vigorava. As práticas representacionais observadas nas reportagens do período, estenderam o rol de atores incluindo empresas de pesquisa, universidades, corporações multinacionais, comunidades indígenas e técnicas e dispositivos de produção, que passaram a coexistir com aqueles mencionados na Versão I. Em virtude desse processo de transbordamento, um novo enquadramento começou a ser desenhado.

Contudo, as bases de conhecimento mobilizadas nos processos de translação para forjar as associações entre os atores migraram para a agroecologia, para a agricultura orgânica e para o campo das políticas públicas. Portanto, uma nova configuração de agenciamento emergiu e se manteve estável no período 2000-2001 permitindo que as práticas representacionais fossem agenciadas de forma a produzir uma versão de mercado cujo foco da narrativa fosse deslocado para os aspectos de produção dos produtos orgânicos. Se a Versão I apontou para a necessidade de uma agricultura alternativa à forma de produção convencional, baseada no uso de agrotóxicos, a Versão II consolidou a agricultura orgânica como solução tecnicamente viável. Como desdobramento, as reportagens sobre produtos orgânicos ganharam maior espaço na revista.

De forma similar ao que ocorreu na transição da Versão I para a Versão II, as práticas representacionais da Versão III também provocaram uma desestabilização no enquadramento até então existente. Porém, ao contrário do que ocorreu na Versão II, alguns atores foram 
deslocados para a margem, ou seja, o processo de overflowing concorreu para que o novo enquadramento fosse estabelecido de forma mais restritiva. No período 2002-2007, as práticas representacionais retrataram majoritariamente atores como empresas, executivos, consumidores, organizações de diversas naturezas (como, por exemplo, o Sebrae e a SNA), feiras de negócios e dispositivos associados a produtos (como embalagens).

Importante ressaltar que apesar de presente, o pequeno produtor, o agricultor retratado nas duas primeiras versões, perdeu relevância e foi um dos atores deslocados para margem. Isso pode ser explicado quando observado que as bases de conhecimento mobilizadas nos processos de translação migraram para o campo da gestão, economia e estatística. O pequeno produtor, portanto, era tido como um ator estranho associado às práticas de agricultura orgânica e/ou agroecológica e que deveria superar esta condição adotando práticas mais empresarias capazes de reconhecer os aspectos mercadológicos do mercado de produtos orgânicos. Dessa forma, estaria alinhado com a narrativa produzida por esta nova configuração de agenciamento segundo a qual, o mercado em questão, é um nicho cujas oportunidades deverão ser exploradas em função do seu potencial de lucratividade.

Também foi possível identificar na Versão III que pesquisadores, empresas de pesquisa e trabalhadores rurais acompanharam o mesmo movimento do produtor rural, com menções cada vez mais raras. As fotos das hortas cederam espaços aos registros de produções orgânicas em escala industrial. Já as empresas do mercado de orgânicos, que já possuíam presença na Versão II, ganham status de protagonista como constatado na seção "Casos de Sucesso". Importante ressaltar que os atores identificados na Versão I, em boa parte, ainda integram a configuração do agenciamento da Versão III, porém mantêm relações mais frágeis com as bases de conhecimento o que explicaria sua condição de marginalidade ao serem retratado pelas práticas representacionais. Existe a possibilidade de constituírem agenciamentos alternativos, porém domesticados, associados às bases de conhecimento das primeiras versões, conforme mostraram as raras reportagens que abordaram questões como segurança e soberania alimentar, temas amplamente discutidos no âmbito da agroecologia (MOURA, 2017).

O quadro 2 apresenta a narrativa de cada versão de mercado produzida pelo agenciamento das práticas representacionais sendo estas últimas, discriminadas por bases de conhecimento, registros fotográficos, as seções editoriais onde foram publicadas a maioria das reportagens e os espaços de página que ocuparam.

Quadro 2. Elementos do agenciamento sociotécnico, práticas representacionais e versões de mercado.

\begin{tabular}{|l|l|l|l|}
\hline Versões de Mercado & Versão I & Versão II & Versão III \\
\hline
\end{tabular}




\begin{tabular}{|c|c|c|c|}
\hline & (1990-1999) & $(2000-2001)$ & $(2002-2007)$ \\
\hline $\begin{array}{l}\text { Agenciamento } \\
\text { Sociotécnico }\end{array}$ & $\begin{array}{l}\text { Narrativa: mercado de } \\
\text { produtos orgânicos emerge } \\
\text { em contraposição ao } \\
\text { sistema convencional de } \\
\text { produção de alimentos } \\
\text { baseado em agrotóxicos, } \\
\text { que produz consequências } \\
\text { nocivas a agricultores, } \\
\text { consumidores e ao meio } \\
\text { ambiente. }\end{array}$ & 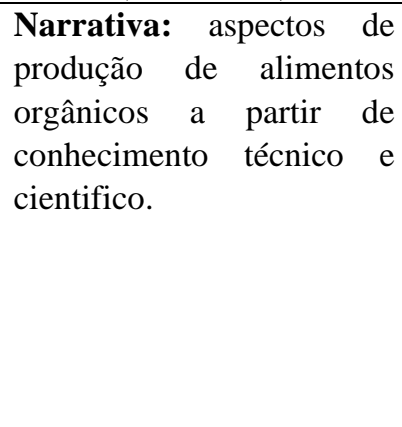 & $\begin{array}{l}\text { Narrativa: o mercado de } \\
\text { produtos orgânicos como } \\
\text { oportunidade de negócios } \\
\text { em contexto } \\
\text { sustentabilidade e de } \\
\text { favorecimento } \\
\text { consumidor. }\end{array}$ \\
\hline $\begin{array}{c}\text { Práticas } \\
\text { Representacionais }\end{array}$ & $\begin{array}{l}\text { Base de Conhecimento: } \\
\text { administração pública, } \\
\text { economia, ecologia/ meio } \\
\text { ambiente, agrobiologia. } \\
\text { Fotos: representações de } \\
\text { hortas e pragas. } \\
\text { Seções editorias das } \\
\text { reportagens: extensão } \\
\text { rural, controle biológico, } \\
\text { horticultura. } \\
\text { Espaço nas páginas da } \\
\text { revista: disputa espaços } \\
\text { com outros temas da seção. }\end{array}$ & $\begin{array}{l}\text { Base de Conhecimento: } \\
\text { agroecologia, agricultura } \\
\text { orgânica e políticas } \\
\text { públicas. } \\
\text { Fotos: representações de } \\
\text { pesquisadores, } \\
\text { agricultores, estudantes, } \\
\text { produtos, dispositivos e } \\
\text { sistemas de produção. } \\
\text { Seções editoriais das } \\
\text { reportagens: agricultura } \\
\text { orgânica, agroecologia e } \\
\text { boletim informativo do } \\
\text { centro nacional de pesquisa } \\
\text { de agrobiologia. } \\
\text { Espaços nas páginas da } \\
\text { revista: seção temática } \\
\text { própria. }\end{array}$ & $\begin{array}{l}\text { Base de Conhecimento: } \\
\text { economia, estatística e } \\
\text { gestão de agronegócio. } \\
\text { Fotos: representações de } \\
\text { empresas, empresários, } \\
\text { sistemas de produção do } \\
\text { campo e da indústria, } \\
\text { produtos (in natura e } \\
\text { processados). } \\
\text { Seções editoriais das } \\
\text { reportagens: } \\
\text { agronegócios } \\
\text { biotecnologia, casos de } \\
\text { sucesso. } \\
\text { Espaços nas páginas da } \\
\text { revista: seção temática } \\
\text { própria }\end{array}$ \\
\hline
\end{tabular}

Fonte: Elaborado pelos autores.

\section{CONSIDERAÇÕES FINAIS}

O presente artigo tem como objetivo investigar como o agenciamento das práticas representacionais identificadas nas reportagens da revista A Lavoura, no período 1990-2007, produziu versões do mercado de produtos orgânicos. Para tanto, recorreu-se a dois conceitos do movimento intitulado Estudos Construtivistas de Mercado em marketing (HARRISON; KJELBERG, 2016; STIGZELIUS, 2018): o de agenciamento sociotécnico (ÇALISKAN; CALLON, 2010) e o de práticas de mercado, especificamente, o de prática representacional (KJELBERG; HELGESSON, 2006; 2007a). A partir desses dois conceitos, entende-se que o agenciamento das práticas representacionais produz de determinada versão de mercado.

Como a investigação foi baseada em dados do passado, optou-se pela adoção de uma perspectiva histórica reorientacionista inspirada na proposta de Durepos e Mills (2011). Desta forma, o passado é visto não a partir de uma ontologia realista, mas como uma construção 
sociomaterial cujas associações entre as práticas de atores humanos e não-humanos configuram diferentes versões do passado. Embora existam pesquisas associadas aos Estudos Construtivistas de Mercado que assumiram prioritariamente uma perspectiva histórica (COCHOY et al., 2018; GEIGER; FINCH, 2016; HAGBERG, 2016), elas não problematizam nem deixaram claro a forma com que o conhecimento histórico sobre mercado foi produzido. Foi a observação desta lacuna somada ao fato de existir uma proposta assentada sobre pressupostos da teoria ator-rede (DUREPOS; MILLS, 2011), também comuns aos Estudos Construtivistas de Mercado, que justificou a opção pela perspectiva histórica reorientacionista.

O corpus da pesquisa, formado por reportagens relacionadas com o mercado de produtos orgânicos, foi organizado em três versões de mercado delimitadas por três períodos específicos de tempo. A Versão I (1990-1999), expressou uma narrativa em que o referido mercado se estabelecia como alternativa aos efeitos negativos causados aos consumidores, aos trabalhadores e ao meio ambiente pela forma convencional de produção de alimentos, baseada no uso de agrotóxicos. Já na Versão II (2000-2001), a narrativa se voltou aos aspectos técnicos e científicos da produção orgânica. Por fim, a Versão III (2002-2007), produziu uma narrativa que retratava o mercado de produtos orgânicos como um nicho específico que apresentava atraentes oportunidades de negócio em razão do seu potencial econômico.

Essas versões de mercado foram produzidas por diferentes configurações de agenciamento das práticas representacionais que retratavam os atores (humanos e nãohumanos) em cada período. As associações estabelecidas entre os atores contaram com diversos processos de translação com destaque para aqueles vinculados a diferentes bases de conhecimento. Desta forma, a configuração do agenciamento das práticas representacionais que produziu a narrativa da Versão I, teve a presença de atores como produtores rurais, consumidores, hortas, pragas, agrotóxicos, leis entre outros cujas associações foram influenciadas por processos de translação que mobilizaram conhecimentos como administração pública, ecologia e agrobiologia. No caso da Versão II, a inclusão de novos atores como pesquisadores, corporações, comunidades indígenas e dispositivos de sistemas de produção mobilizaram bases de conhecimentos como agroecologia, agricultura orgânica e políticas públicas por meio de processos de translação que implicaram em uma representação dominante de mercado. Por fim, na Versão III, atores como executivos, feiras de negócios, empresas e consumidores tiveram suas associações reforçadas por processos de translação vinculados a bases de conhecimento como gestão, economia e estatística ganhando maior destaque e relevância enquanto que outros foram deslocados para margem. 
A partir das diferentes configurações de agenciamento das práticas representacionais presentes nas reportagens da revista A Lavoura, foi possível identificar a produção de versões hegemônicas e distintas do mercado de produtos orgânicos. Tais versões se diferenciam em função das associações estabelecidas pelos atores por meio de processos de translação que mobilizaram diferentes bases de conhecimento. À medida em que as associações entre os atores fossem asseguradas e estabilizadas ao longo do período de tempo de cada versão, uma representação hegemônica de mercado foi produzida.

Os resultados apresentados sugerem contribuições no âmbito dos Estudos Construtivistas de Mercado em marketing e, de forma mais modesta, para os estudos organizacionais, especificamente para aqueles baseados em pesquisa histórica com lastro na perspectiva reorientacionista. No primeiro caso, contribuem para as pesquisas baseadas em práticas representacionais (RUIZ, 2013; HAGBERG; KJELLBERG, 2015; STIGZELIUS, 2018; RUIZ; KJELLBERG, 2020) à medida em que explica qual a importância destas no processo de formação de mercados localizados no passado. Também contribuem para linhas de pesquisas baseadas no conceito de agenciamento sociotécnico (HAGBERG, 2016; COCHOY et al., 2016; ARAUJO; KJELLBERG, 2016) ao pontar a existência das dinâmicas de inclusão e de marginalização de atores humanos e não-humanos presentes em sua configuração. Já no segundo, a contribuição está associada a operacionalização da proposta de Durepos e Mills (2011) para investigações sobre formação de mercado baseadas em dados históricos.

De forma mais específica, a operacionalização dos conceitos utilizados também permite apontar contribuições de natureza teórica. As práticas representacionais não podem ser consideradas tão somente descrições ou abstrações sobre o funcionamento do mercado que contribuem diretamente para a própria constituição do fenômeno (KJELBERG; HELGESSON, 2006; 2007a). Os resultados da pesquisa revelaram uma dimensão política, de poder e ideológica que deve ser considerada nos estudos sobre formação de mercado, com implicações sobre as outras práticas não contempladas na presente pesquisa (práticas de troca e normativa). Neste sentido, o processo de marketization ou de formação de mercado (ÇALISKAN; CALLON, 2010; CALLON, 2016) parece limitado se entendido apenas como um processo de organização de atividades econômicas. A incorporação da dimensão política às práticas representacionais ajudaria inclusive a superar críticas já destinadas às propostas de Callon sobre uma suposta neutralidade e aversão a questões políticas e de poder (BUTLER, 2010; PELLANDINI-SIMÁNYL, 2016). Adicionalmente, também ajudaria a explorar a formação de agenciamentos de mercado hegemônicos e alternativos com suas respectivas representações e formas de coexistência. 
As limitações da pesquisa estão associadas ao fato ter concentrado esforços em uma única fonte de dados, a revista A Lavoura, bem como na natureza interpretativa que cercou a produção das narrativas das versões de mercado. Neste último caso, entende-se que os autores são parte integrante da pesquisa, portanto, integram a própria rede que constroem (DUREPOS; MILLS, 2011) sendo o exercício da reflexividade fundamental em todas as etapas desta pesquisa.

As possibilidades para pesquisas futuras são diversas: como uma representação hegemônica de mercado influencia os rumos dos processos de formulação de políticas públicas? Quais as consequências da marginalização de atores nas representações de mercado? Como o agenciamento de práticas representacionais poderia assegurar a existência de versões alternativas de mercado? Qual o papel que as outras práticas de mercado possuem na configuração dos agenciamentos? Qual a importância que versões de mercado do passado possuem em tempos atuais? Como a performatividade do conhecimento científico influencia a formação de mercado? Como todas as questões até aqui apresentadas se relacionam com questões políticas, sociais, ideológicas e geopolíticas? Esses questionamentos podem orientar futuras pesquisas empíricas ou ensaios teóricos para não só promover maior conhecimento sobre o processo de formação de mercados, mas contribuir para que as práticas envolvidas sejam mais justas e democráticas.

\section{REFERÊNCIAS}

AHRNE, G.; ASPERS, P.; BRUNSSON, N. The organization of markets. Organization Studies, vol. 36, $\mathrm{n}^{\circ} 1,2014$.

ARAUJO, L.; FINCH, J.; KJELLBERG, H. Reconnecting marketing to markets. Oxford: Oxford University Press, 2010.

ARAUJO, L.; KJELLBERG, H. Enacting novel agencement: the case of Frequent Flyer schemes in the US airline industry (1981-1991). Consumption Markets \& Culture, vol. 19, $\mathrm{n}^{\mathrm{o}} 1,2016$.

ARAUJO, L.; KJELLBERG, H. Shaping exchanges, performing markets: the study of market-ing practices. In.: MACLARAN, P.; SAREN, M.; STERN, B.; TADAJEWSKI, M. The SAGE Handbook of Marketing Theory. London: SAGE Publications Ltd., 2009.

ARAUJO, L.; KJELLBERG, H.; SPENCER, R. Market practices and forms: introduction to special issue. Marketing Theory, vol. 8, $\mathrm{n}^{\circ} 1,2008$.

BALMER, J.; BURGHAUSEN, M. Marketing, the past and corporate heritage. Marketing Theory, vol.19, n² 2019. 
BARNEY, J.; HESTERLY, W. Economia das organizações: entendendo a relação entre as organizações e a análise econômica. In: CALDAS, M.; FACHIN, R.; FISCHER, T.

Handbook de Estudos Organizacionais - Ação e Análise Organizacionais. Vol.3. São Paulo: Atlas, 2004.

BARROS, A. Archives and the "archive": dialogue and an agenda of research in organization studies. O \& S, vol. 23, nº 79, 2016.

BARROS, A; CARNEIRO, A. Estado, formação de gestores e a pós-graduação em administração brasileira: o caso PNTE. Revista de Administração Pública, vol. 52, nº 5 , 2018.

BARROS, A.; CARNEIRO, A.; WANDERLEY, S. Organizational archives an historical narratives - practicing reflexivity in (re)constructing the past from memories and silences. Qualitative Research in Organizations and Management: An International Journal, vol. 14, n³, 2019.

BAUER, M.; GASKELL, G. Pesquisa qualitativa, com texto, imagem e som. Petrópolis: Vozes, 2002.

BLANCHET, V.; DEPEYRE, C. Exploring the shaping of markets through controversies. Journal of Macromarketing, vol. 36, $\mathrm{n}^{\circ} 1,2015$.

BOLTANSKI, L.; THÉVENOT, L. On justification: economies of worth. Princeton: Princeton University Press, 2006.

BOOTH, C.; ROWLINSON, M. Management and organizational history: prospects. Management \& Organizational History, vol. 1, nº $1,2006$.

BOSCHI, M. O ensino de marketing no Brasil: história, memória e esquecimento ou porque este artigo não é de marketing. In: XLII do Enanpad, 2018. Anais...2018.

BRASIL. Lei n ${ }^{\circ} 10.831$, de 23 de dezembro de 2003. Dispõe sobre a agricultura orgânica e dá outras providências. Diário Oficial, Brasília, p.8, 24/12/2003.

BRASIL. Lei $N^{\circ}$ 6.323, de 27 de dezembro de 2007. Regulamenta a Lei $\mathrm{n}^{\circ} 10.831$, de 23 de dezembro de 2003, que dispõe sobre agricultura orgânica, e dá outras providências. Diário Oficial, Brasília, p.2-8, 24/12/2007.

BURR, T. Market-Widening: shaping total market demand for French and American bicycles circa 1890. Marketing Theory, vol. 14, $\mathrm{n}^{\circ} 1,2014$.

BUTLER, J. Performative agency. Journal of Cultural Economy, vol. 3, n²2, 2010.

ÇALISKAN, K.; CALLON, M. Economization, part 2: a research program for the study of markets. Economy and Society, vol. 39, vol. 1, 2010. 
CALLON, M. "Some elements of a sociology od translation: domestication of the scallops and the fishermen of St-Brieuc. In: LAW, J. Power, Action and Belief: A New Sociology of Knowledge. London: Routledge, 1986.

CALLON, M (ed.). The Laws of Markets. Oxford: Blackwell Publishers, 1998.

CALLON, M. 'Actor-Network Theory - The Market Test. In: LAW, J.; HASSARD, J. Actor Network Theory and After. Oxford: Blackwell Publishing, 1999.

CALLON, M. Qu'est-ce qu'un agencement marchand? In: CALLON, M et al. Sociologie des agencement marchands: textes choisis. Paris: Presses des Mines, 2013.

CLARK, P.; ROWLINSON, M. The treatment of history in organization studies: towards an 'Historic Turn'. Business History, vol. 46, n³, 2004.

COCHOY, F. Reconnecting 'marketing to market-things': how grocery equipment drove modern consumption (Progressive Grocer, 1929-1959). In: ARAUJO, L; FINCH, J; KJELLBERG, H. (eds.). Reconnecting marketing to markets. Oxford: Oxford University Press, 2010.

COCHOY, F.; HAGBERG, J.; KJELLBERG, H. The ethno-graphy of prices: on the fingers of the invisible hand (1922-1947). Organization, vol. 0, nº, 2018.

COCHOY, F.; TROMPETTE, P.; ARAUJO, L. From market agencements to market agencing: an introduction. Consumption Markets \& Culture, vol. 19, nº 1, 2016.

CORRIGAN, L. Accounting practice and the historical turn: performing budget histories. Management \& Organizational History, vol. 11, n², 2016.

COSTA, A.; BARROS, D.; MARTINS, P. Perspectiva histórica em administração: novos objetos, novos problemas, novas abordagens. RAE, vol. 50, n³ 2010.

COSTA, A; SILVA, M. Novas fontes, novas versões: contribuições do acervo da Comissão Nacional da Verdade. RAC, vol. 21, nº 2, 2017.

COSTA, A.; SILVA, M. A pesquisa histórica em administração: uma proposta para práticas de pesquisa. RAEP, vol. 20, nº1, 2019.

DUREPOS, G.; MILLS, A. Actor-network theory, ANTi-History and critical organizational historiography. Organization, vol. 19, nº, 2011.

FERREIRA, F. Potencialidades da análise histórica nos estudos organizacionais brasileiros. RAE, vol. 50, $\mathrm{n}^{\circ} 1,2010$.

FLIGSTEIN, N. Market as politics: a political-cultural approach to market institutions. American Sociological Review, vol. 61, nº 4, 1996.

FONSECA, M. Agricultura orgânica: regulamentos técnicos para acesso aos mercados dos produtos orgânicos no Brasil. Niterói: PESAGRO-RIO, 2009. 
GEIGER, S.; FINCH, J. Promissories and pharmaceutical patents: agencing markets through public narratives. Consumption Markets \& Culture, vol. 19, nº $1,2016$.

GEIGER, S.; GROSS, N. Market failures and market framings: can a market be transformed from the inside? Organizations Studies, vol.0, nº, 2017.

GEIGER, S.; HARRISON, D.; KJELLBERG, H.; MALLARD, A. Being concerned about markets. In.: GEIGER, S.; HARRISON, D.; KJELLBERG, H.; MALLARD, A. Concerned markets: economic ordering for multiple values. Cheltenham: Edward Elgar Publishing Limited, 2014.

GHERARDI, S. To start practice theorizing anew: the contribution of the concepts of agencement and formativeness. Organization, vol. 23, $\mathrm{n}^{\circ}$ 5, 2016.

GODFREY, P.; HASSARD, J.; O’CONNOR, E.; ROWLINSON, M.; RUEF, M. What is organizational history? Toward a creative synthesis of history and organization studies. Academy of Management Review, vol. 41, nº 4, 2016.

HAGBERG, J. Agencing practices: a historical exploration of shopping bags. Consumption Markets \& Culture, vol. 19, nº1, 2016.

HAGBERG, J.; KJELLBERG, H. How much is it? Price representations practices in retail markets. Marketing Theory, vol. 15, $\mathrm{n}^{\circ}$ 2, 2015.

HARRISON, D.; KJELLBERG, H. How users shape markets. Marketing Theory, vol.16, $\mathrm{n}^{\circ} 4,2016$.

HOLLANDER, S.; RASSULI, K.; JONES, D.; DIX, L. Periodization in Marketing History. Journal of Macromarketing, vol. 25, $\mathrm{n}^{\circ} 1,2005$.

KJELLBERG et al. Markets futures/future markets: research directions in the study of markets. Marketing Theory, vol. 12, nº12, 2012.

KJELLBERG, H.; HELGESSON, C. Multiple versions of markets: multiplicity and performativity in the market practice. Industrial Marketing Management, vol. 35, $n^{\circ} 7$, 2006.

KJELLBERG, H.; HELGESSON, C. On the nature of markets and their practices. Marketing Theory, vol. 7, n², 2007a.

KJELLBERG, H.; HELGESSON, C.F. The mode of exchange and shaping of markets: distributor influence in the Swedish post-war food industry. Industrial Marketing Management, vol. 36, $\mathrm{n}^{\circ} 7,2007 \mathrm{~b}$.

KJELLBERG, H.; OLSON, D. Joint markets: how adjacent markets influence the formation of regulated markets. Marketing Theory, vol. 17, $\mathrm{n}^{\mathrm{o}}$ 1, 2017.

KOTLER, P.; KELLER, K. Administração de Marketing. São Paulo: Pearson Prentice Hall, 2006. 
LAW, J.; URRY, J. Enacting the social. Economy and Society, vol. 33, nº 3, 2004.

LINDEMAN, S. Market formation in subsistence contexts: a study of informal waste trade practices in Tanzania and Brazil. Consumption Markets \& Culture, vol. 15, nº 2, 2012.

MASON, K.; KJELLBERG, H.; HAGBERG, J. Exploring the performativity of marketing: theories, practices and devices. Journal of Marketing Management, vol. 31, nº1-2, 2015.

MEDEIROS, J.; VIEIRA, F.; NOGAMI, V. A construção do mercado editorial eletrônico no Brasil por meio das práticas de marketing. RAM, vol. 15, nº 1, 2014.

MILLS, A.; SUDDABY, R.; FOSTER, W.; DUREPOS, G. Re-visiting the historic turn 10 years later: current debates in management and organizational history - an introduction. Management \& Organizational History, vol. 11, nº2, 2016.

MOL, M. Ontological politics: a word and some questions. In: LAW, J.; HASSARD, J. (eds). Actor Network theory and After. Oxford: Blackwell Publishers, 1999.

MOURA, I. Antecedentes e aspectos fundantes da agroecologia e da produção orgânica na agenda das políticas públicas no Brasil. In: SAMBUICHI et al. (org). A política nacional de agroecologia e produção orgânica no Brasil: uma trajetória de luta pelo desenvolvimento rural sustentável. Brasília: Ipea, 2017.

PELLANDINI-SIMÁNYI, L. Non-marketizing agents in the study of markets: competing legacies of performativity and actor-network-theory in marketization research program. Journal of Cultural Economy, vol. 9, nº, 2016.

PFEFFERMAN, T. Reassembling the archives: business history knowledge production from actor-network perspective. Management \& Organizational History, vol.11, nº $4,2016$.

PINTON, F.; YANNICK, S. Soberania versus segurança alimentar no Brasil: tensões e oposições em torno da agroecologia como projeto. Estudos Sociedade \& Agricultura, vol. $27, \mathrm{n}^{\circ} 1,2019$.

RAUD-MATTEDI, C. Análise crítica da sociologia econômica de Mark Granovetter. Política \& Sociedade, $n^{\circ} 6,2005$.

RINALLO, D.; GOLFETTO, F. Representing markets: the shaping of fashion trends by French and Italian fabric companies. Industrial Marketing Management, vol. 35, nº7, 2006.

ROSCOE, P. 'Elephants can't gallop': performativity, knowledge and power in the market for lay-investing. Journal of Marketing Management, vol. 31, nº1-2, 2015.

RUIZ, C. Assembling market representations. Marketing Theory, vol. 13, n³, 2013.

RUIZ, C; KJELLBERG, H. Feral segmentation: how cultural intermediaries perform market segmentation. Marketing Theory, 2020. Disponível em:

<https://doi.org/10.1177/1470593120920330>. Acesso em 7 de jun. de 2020. 
SAUERBRONN, F.; FARIA, A. A utilização do método histórico em pesquisa acadêmica de marketing. Estratégia e Negócios, v.2, n.2, 2009.

SMELSER, N.; SWEDBERG, R. The handbook of economic sociology. Princeton: Princeton University Press, 2005.

SNA - Sociedade Nacional de Agricultura. SNA comemora com otimismo seus 122 anos. Disponível em: https://www.sna.agr.br/sna-comemora-com-otimismo-seus-122-anos/ Acesso em: 31 out 2019.

STIGZELIUS, I. Representing the political consumer: liquid agencies in the production of consumer voice. Consumption Markets \& Culture, v. 21, n.5, 2018.

SWEDBERG, R. Principles of economic sociology. Princeton: Princeton University Press, 2003.

TADAJEWSKI, M.; JONES, D. Historical research in marketing theory and practice. Journal of Marketing Management, vol. 30, nº 11/12, 2014.

USDIKEN, B.; KIESER, A. Introduction: history in organization studies. Business History, vol. 46, n³, 2004.

VIEIRA, M. Por uma boa pesquisa (qualitativa) em administração. In.: VIEIRA, M.;

ZOUAIN, D. (org.). Pesquisa qualitativa em administração. Rio de Janeiro: Editora FGV, 2004.

WANDERLEY, S.; BARROS, A. Decoloniality, geopolitics of knowledge and historic turn: towards a Latin American agenda. Management \& Organizational History, vol. 14, nº 1 , 2018.

WEATHERBEE, T. Caution! This historiography makes wide turns: historic turns and breaks in management and organization studies. Management \& Organizational History, vol. 7, $\mathrm{n}^{\circ}$ 3,2012 .

YIN, R. Pesquisa qualitativa do início ao fim. Porto Alegre: Penso, 2016. 